\title{
Temporal invariance for picture-word translation: Evidence from drawing-writing and naming-reading tasks
}

\author{
PAUL C. AMRHEIN \\ University of New Mexico, Albuquerque, New Mexico
}

\begin{abstract}
In two experiments, picture-word processing was investigated using graphic (drawing-writing) and verbal (naming-reading) production tasks. In both experiments, the subjects drew a picture or wrote a word upon presentation of a picture or a word stimulus. Additionally, the subjects in Experiment 2 named a picture or read a word stimulus. Production onset latency was assessed. In both experiments, drawing production was initiated more slowly than was writing production. In Experiment 2, graphic production was initiated more slowly than was verbal production. Equivalent latency increases were found for cross-modality trials (e.g., drawing a picture given a word stimulus) relative to within-modality trials (e.g., drawing a picture given a picture stimulus), independent of stimulus modality (word or picture), production modality (word or picture), or task (graphic or verbal production). These results strongly support a mathematical model which incorporates temporal invariance for pictures and words concerning encoding, cross-modality transfer, and retrieval.
\end{abstract}

Under various guises, the picture-naming task has remained a popular methodology with which to assess picture processing and subsequent lexical access (see Glaser, 1992, for a review). These guises include dual-stimulus priming tasks (e.g., Bajo, 1988; Biggs \& Marmurek, 1990; McCauley, Parmalee, Sperber, \& Carr, 1980; McEvoy, 1988; Levelt et al., 1991; Schriefers, Meyer, \& Levelt, 1990; Wheeldon \& Monsell, 1992), dualstimulus, Stroop-like interference tasks (e.g., Glaser \& Dungelhoff, 1984; Glaser \& Glaser, 1989; La Heij, 1988; Smith \& Magee, 1980), and the focus of the present paper, single-stimulus picture-naming, word-reading (henceforth, naming-reading) tasks (e.g., Cattell, 1886; Fraisse, 1960, 1964, 1967, 1969; Potter \& Faulconer, 1975; Theios \& Amrhein, 1989, Experiment 1).

In general, picture-naming tasks have a distinct advantage over dual-stimulus comparison tasks also used in picture-word processing research, such as categorization (e.g., Harris, Morris, \& Bassett, 1977; Pellegrino, Rosinski, Chiesi, \& Siegel, 1977; te Linde, 1982) and semantic matching (e.g., Theios \& Amrhein, 1989, Experiment 2). That is, while dual-stimulus comparison tasks allow inferences concerning encoding and access of verbal and pictorial representations via semantic memory, these inferences may be influenced by the effects of decision subprocesses also required for task performance. By contrast, production tasks (heretofore primarily concerning pronunciation) generally provide a more direct

Correspondence concerning this article should be addressed to Paul C. Amrhein, Department of Psychology, University of New Mexico, Albuquerque, NM 87131 (e-mail: amrhein@hydra.unm.edu). manner of assessing representational access (see, e.g., Balota \& Chumbley, 1984, 1985). For example, in the case of the naming-reading task, the difference between onset latency to name a picture and onset latency to read that picture's name can be used to estimate the latency to access the picture's name via semantic memory (Glaser, 1992; Theios \& Amrhein, 1989).

Theios and Amrhein (1989) proposed a picture-word processing model similar to the one depicted in Figure 1. This theoretical model assumes that pictures and words are initially encoded independent of modality in an "early visual processor" and then subsequently encoded in modality-specific processors (i.e., in a "surface pictorial processor" and a "surface linguistic processor," respectively). Theios and Amrhein (1989) found that when picture and word stimuli denote the same familiar concept, are equated for overall area, and have subtended visual angles that fall within the range of $2.2^{\circ}-8.0^{\circ}$, their encoding latencies are equivalent. In addition, when these conditions are met, the latency to transfer processing of the picture stimulus from the surface pictorial processor to the surface linguistic processor via an amodal "abstract conceptual processor" (i.e., semantic memory)-in order to access that picture's phonological code-can be estimated using a naming-reading task (see, e.g., Cattell, 1886; Fraisse, 1969; Theios \& Amrhein, 1989).

In contrast to the amodal model of Theios and Amrhein (1989) and others (Seymour, 1973, 1979; Snodgrass, $1980,1984)$, Paivio $(1971,1983,1986)$ has proposed a dual-coding model which posits modality-specific processors (and associated memory stores) that are concerned with the representation and processing of different aspects of the meaning of a concept (see Figure 2). These pro- 


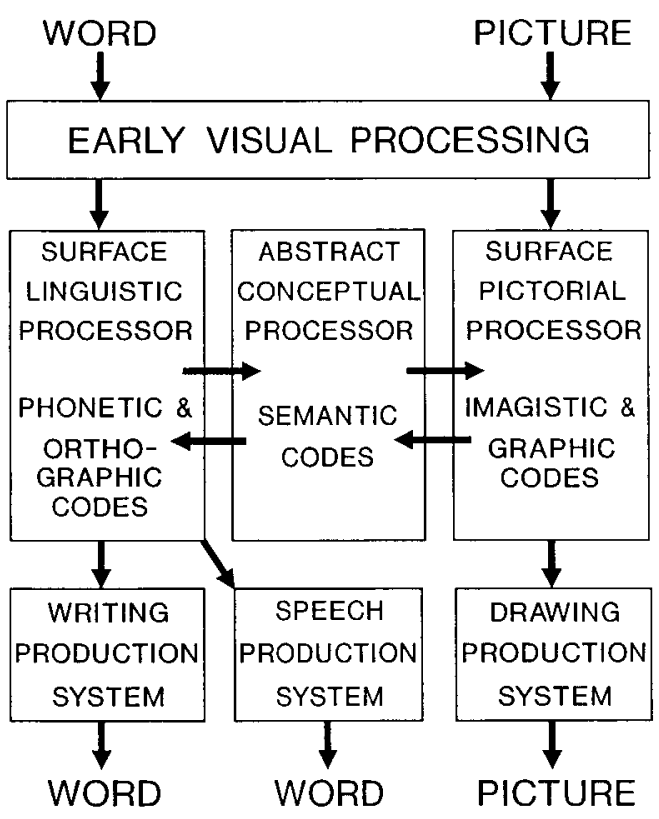

Figure 1. Flow diagram representing the general architecture of the amodal picture-word processing model of Theios and Amrhein (1989), adapted for the drawing-writing task of Experiments 1 and 2 and the naming-reading task of Experiment 2.

cessors exhaust conceptual meaning; there is no need for an amodal conceptual store. For example, the verbal processor deals with such aspects of conceptual meaning as categorical membership (but see te Linde, 1982, for a qualification of this claim), whereas the pictorial processor deals with such aspects of conceptual meaning as relative size of the concept when represented as an object.

Based on research from the episodic memory and imagery literature (see Paivio, 1971, 1986), researchers have suggested that the dual-coding model predicts that accessing a verbal code for a picture stimulus should require less time than accessing an image code for a verbal stimulus (see Pellegrino et al., 1977). The logic for this prediction can be explained by the relationship between probability of process occurrence and latency for that subprocess to take place. Specifically, Paivio (1986) predicts that in a standard episodic memory task, "pictures of common objects would be remembered even better than concrete words on the assumption that subjects are more likely to label pictures spontaneously than they are to image to concrete words"' (p. 160). This suggests that there are at least two subprocesses for a cross-modal translation, one spontaneous and one (or more) nonspontaneous. If so, it follows that, for all relevant subprocesses, the expected latency to carry out a cross-modal translation process (picture to word or word to picture) is a composite function of the probability of the occurrence of a given subprocess and the associated latency of that subprocess (see Falmagne, 1965; Lupker \& Theios, 1975). Given the case in which it is more likely that the spontaneous subprocess, rather than the other nonspontaneous subprocesses (i.e., concerning translation from picture to word), will occur, the expected latency for that case will be less than it will be for the case in which the probability of occurrence of the spontaneous subprocess is not as high, relative to the occurrence of the other nonspontaneous subprocesses (i.e., translation from word to picture). It may be the case that this extension of dual-coding theory does not apply to the prediction of cross-modality transfer latency in a speeded picture-word translation task; if so, then the generality of dual coding in explaining pictureword processing would need to be qualified.

It should be noted that there is another picture-word processing model which posits a memory processor and store that are amodal, but to which pictures have faster access than do words (e.g., Bajo, 1988; Potter \& Faulconer, 1975; Smith \& Magee, 1980). However, support for this theory has been derived primarily from experiments involving either large pictures and small words or pictures uncontrolled for featural similarity, confounds which, when removed, result in no such advantage for pictures (see Snodgrass \& McCullough, 1986; Theios \& Amrhein, 1989). Furthermore, with the prediction of the picture advantage removed, this type of model becomes functionally equivalent to the amodal models of Seymour

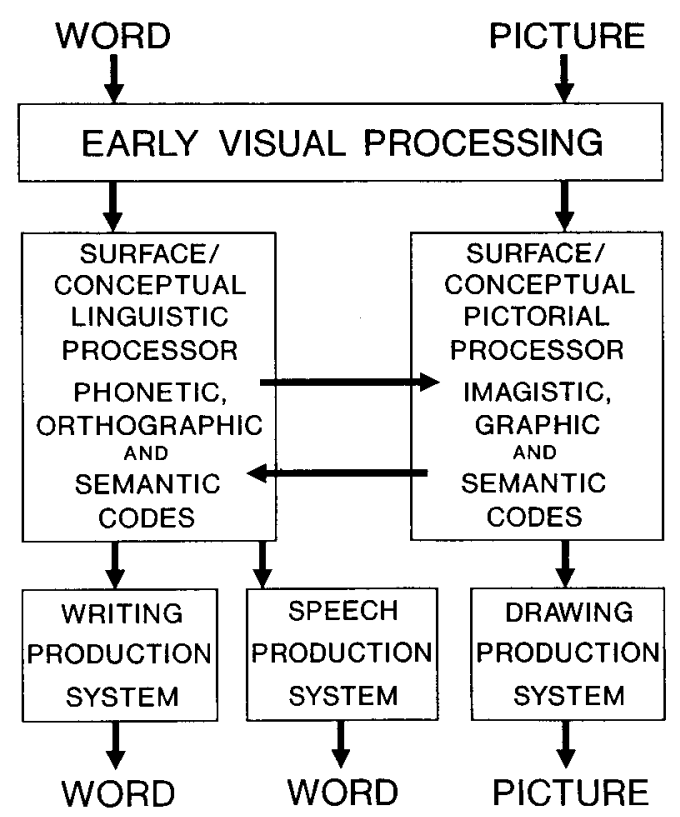

Figure 2. Flow diagram representing the general architecture of the dual-coding model adapted for the drawing-writing task of Experiments 1 and 2 and the naming-reading task of Experiment 2. 
(1973, 1979), Snodgrass (1980), and Theios and Amrhein (1989).

The naming-reading task discussed above allows assessment only of the access latency of a picture's name from that picture. A more comprehensive task would assess both this latency and access latency of a picture from that picture's name. Accordingly, in the current investigation a drawing-writing task was used in Experiment 1 and then contrasted with the naming-reading task in Experiment 2 . In the drawing-writing task, the subjects either drew a picture from a picture or word stimulus or wrote a word from a word or picture stimulus. The dependent measure was response onset latency, in terms of the time to begin writing a word or drawing a picture upon stimulus presentation. This drawing-writing task provides a direct assessment of stimulus encoding and cross-modality transfer subprocesses, independent of stimulus and task modality. As will be detailed below, this task allows a critical test of the amodal and dual-coding models that concerns the functioning of these subprocesses.

Equations 1-4 give the related input stimulus encoding, cross-modality access, output representation retrieval, and production onset latencies incurred by the conditions of this task:

$$
\begin{aligned}
\operatorname{Write}\left(W_{\mathrm{i}}, W_{\mathrm{j}}\right) & =t_{\mathrm{E}}\left(W_{\mathrm{i}}\right) \quad+t_{\mathrm{LO}}+t_{\mathrm{O}}\left(W_{\mathrm{j}}\right) \\
\operatorname{Write}\left(P_{\mathrm{i}}, W_{\mathrm{j}}\right) & =t_{\mathrm{E}}\left(P_{\mathrm{i}}\right)+t_{\mathrm{T}}\left(P_{\mathrm{i}}, W_{\mathrm{j}}\right)+t_{\mathrm{LO}}+t_{\mathrm{O}}\left(W_{\mathrm{j}}\right) \\
\operatorname{Draw}\left(W_{\mathrm{i}}, P_{\mathrm{j}}\right) & =t_{\mathrm{E}}\left(W_{\mathrm{i}}\right)+t_{\mathrm{T}}\left(W_{\mathrm{i}}, P_{\mathrm{j}}\right)+t_{\mathrm{P}}+t_{\mathrm{O}}\left(P_{\mathrm{j}}\right) \\
\operatorname{Draw}\left(P_{\mathrm{i}}, P_{\mathrm{j}}\right) & =t_{\mathrm{E}}\left(P_{\mathrm{i}}\right)
\end{aligned}
$$

Here, Write $\left(W_{\mathrm{i}}, W_{\mathrm{j}}\right)$ and $W r i t e\left(P_{\mathrm{i}}, W_{\mathrm{j}}\right)$ represent the total time to initiate the writing of a word, $W_{\mathrm{j}}$, from, respectively, a corresponding (i.e., same-concept) word stimulus $\left(W_{\mathrm{i}}\right)$ and a corresponding picture stimulus $\left(P_{\mathrm{i}}\right)$. $\operatorname{Draw}\left(W_{\mathrm{i}}, P_{\mathrm{j}}\right)$ and $\operatorname{Draw}\left(P_{\mathrm{i}}, P_{\mathrm{j}}\right)$ represent the total time to initiate the drawing of a picture, $P_{\mathrm{j}}$, from, respectively, a corresponding (i.e., same-concept) word stimulus $\left(W_{\mathrm{i}}\right)$ and a corresponding picture stimulus $\left(\boldsymbol{P}_{\mathrm{i}}\right)$. These formulas are interpreted for amodal and dual-coding models as follows: For the amodal model, the time to encode a word or picture stimulus into its corresponding surface processor (linguistic or pictorial) is given, respectively, by the parameters $t_{\mathrm{E}}\left(W_{\mathrm{i}}\right)$ and $t_{\mathrm{E}}\left(P_{\mathrm{i}}\right)$. In the case of writing a word from a picture stimulus (Equation 2) or drawing a picture from a word stimulus (Equation 3), the additional time to transfer information from the surface processor (linguistic or pictorial) corresponding to the modality of the input stimulus to the surface processor (pictorial or linguistic) corresponding to the modality of the output production, via the abstract conceptual processor, is given, respectively, by the transfer parameters $t_{\mathrm{T}}\left(W_{\mathrm{i}}, P_{\mathrm{j}}\right)$ and $t_{\mathrm{T}}\left(P_{\mathrm{i}}, W_{\mathrm{j}}\right)$. The additional latency to retrieve an orthographic code from the surface linguistic processor corresponding to the word to be written is given by $t_{\mathrm{LO}}$. The additional latency to retrieve a graphic code from the surface pictorial processor corresponding to the picture to be drawn is given by $t_{\mathrm{P}}$. Lastly, the additional time to prepare for and initiate a production, either writing a word or drawing a picture, is given by the parameters $t_{\mathrm{O}}\left(W_{\mathrm{j}}\right)$ and $t_{\mathrm{O}}\left(P_{\mathrm{j}}\right)$, corresponding to the processing incurred, respectively, by the writing and the drawing production systems (see Figure 1).

The dual-coding model differs from the amodal model in interpretation of Equations 1-4 as follows: The time to encode a word or picture stimulus into its corresponding surface/conceptual processor (linguistic or pictorial) is given, respectively, by the parameters $t_{\mathrm{E}}\left(W_{\mathrm{i}}\right)$ and $t_{\mathrm{E}}\left(P_{\mathrm{i}}\right)$. In the case of writing a word from a picture stimulus (Equation 2) or drawing a picture from a word stimulus (Equation 3), the additional time to transfer information from the surface/conceptual processor (linguistic or pictorial) corresponding to the modality of the input stimulus to the surface/conceptual processor (pictorial or linguistic) corresponding to the modality of the output production is given, respectively, by the transfer parameters $t_{\mathrm{T}}\left(W_{\mathrm{i}}, P_{\mathrm{j}}\right)$ and $t_{\mathrm{T}}\left(P_{\mathrm{i}}, W_{\mathrm{j}}\right)$. Lastly, $t_{\mathrm{Lo}}$ corresponds to the additional time to retrieve an orthographic code from the surface/conceptual linguistic processor; $t_{\mathrm{P}}$ corresponds to the additional time taken to retrieve a graphic code from the surface/conceptual pictorial processor.

It should be noted that Equations 1-4 reflect related findings in the picture-naming literature. For example, it has been found that while picture naming requires semantic memory access, word reading does not (Bajo, 1988; Glaser, 1992). By analogy, Equations $2-3$ posit that for cross-modal conditions (writing a picture's name from that picture and drawing a picture from that picture's name) semantic memory access is involved, but Equations 1 and 4 posit that for within-mode conditions (writing a picture's name from that name and drawing a picture from that picture), no semantic memory access is involved.

Until now, the primary mode of comparing picture-toword and word-to-picture translation has involved contrasting picture-naming latencies with image-generation latencies (see Paivio, 1966, 1986; Paivio, Clark, Digdon, \& Bons, 1989; Snodgrass, 1980). Because comprehensive within-subject contrasts are difficult to find in the literature, contrasting picture-naming and image-generation latencies is problematic because of noncomparable tasks (Snodgrass, 1980). Moreover, the naming-reading task typically involves an observable pronunciation onset response. By contrast, the image-generation task cannot involve a comparable observable response (onset or otherwise). Furthermore, the introspective nature of the image-generation task allows for uncontrolled subject variability in generation strategies, often leading to conflicting results (see Farah \& Kosslyn, 1981; Paivio, 1986). For these reasons, the drawing-writing task offers an improved, balanced solution to the incompleteness of the traditional naming-reading task by providing comparable, observable production responses with which to assess cross-modality translation latency.

The study by Paivio et al. (1989) represents one of the few within-subject, comparable investigations of naming and imaging. In that study, the subjects either named pictures or generated images from picture labels. The de- 
pendent measure was latency to make a manual ready-toproduce response (writing for naming, drawing for image generation). After making this response, the subjects then carried out the corresponding graphic production. Paivio et al. (1989) found that, overall, manual response latencies were equivalent for naming and imaging conditions, suggesting that "referential" processes are reciprocal in process complexity and function. Variation in manual ready-to-name response latency correlated significantly $(r=.87)$ with pronunciation onset latencies for their set of stimuli from earlier unpublished studies. Also, variation in manual ready-to-draw response latency correlated significantly $(r=.59)$ with averaged manual ready-to-name response and pronunciation onset latencies. While these findings appear to refute the cross-modal asymmetry predicted by the dual-coding model as described earlier, it should be pointed out that actual production onset latency was not measured, only latency to make a "readiness" response. In addition, within-mode conditions (generating an image from a picture or reading a picture label) were not assessed in their study, precluding a test of either amodal or dual-coding predictions for cross-modality transfer latency [i.e., $t_{\mathrm{T}}\left(P_{\mathrm{i}}, W_{\mathrm{j}}\right)$ vs. $\left.t_{\mathrm{T}}\left(W_{\mathrm{i}}, P_{\mathrm{j}}\right)\right]$ discussed earlier.

In one of the few investigations of picture-word processing in which actual drawing onset latency was assessed, Seymour (1974) found that drawing from a picture was initiated in much less time than was drawing from a sentence. Here, Seymour proposed that drawing a picture, generally, involves the access and use of a "pictorial code," which represents the "spatial meaning" of that picture in an imagelike format. However, Seymour used relatively complex sentences (e.g., " The circle is inside the square.") and pictures (e.g., 囫) in his study. Such stimuli likely produced an overestimate of the time required to access a cross-modality representation (in this case, a picture) given the added stimulus complexity; indeed, this value-which represents an estimate of $t_{\mathrm{T}}\left(W_{\mathrm{i}}, P_{\mathrm{j}}\right)$ for his stimuli-was $585 \mathrm{msec}$ ! In addition, because this task involved only drawing, only the transfer from a verbal stimulus to a pictorial representation was assessed.

\section{EXPERIMENT 1}

Of particular interest for Experiment 1 was the comparison between the two encoding parameters, $t_{\mathrm{E}}\left(W_{\mathrm{i}}\right)$ and $t_{\mathrm{E}}\left(P_{\mathrm{i}}\right)$, and the two transfer parameters, $t_{\mathrm{T}}\left(W_{\mathrm{i}}, P_{\mathrm{j}}\right)$ and $t_{\mathrm{T}}\left(P_{\mathrm{i}}, W_{\mathrm{j}}\right)$, assessed in the drawing-writing task. (Henceforth, to represent values averaged over stimulus concepts, subscripts $i$ and $j$ will be omitted.) As detailed above, the latencies for picture and word encoding latencies are equivalent under nominally controlled conditions (Theios \& Amrhein, 1989). Furthermore, latencies for crossmodality transfers have been inferred from a semantic matching task to be equivalent [i.e., $\left.t_{\mathrm{T}}(P, W)=t_{\mathrm{T}}(W, P)\right]$, as predicted by Theios and Amrhein. By contrast, the dual-coding model suggested by the episodic memory and imagery literature predicts that $t_{\mathrm{T}}(P, W)<t_{\mathrm{T}}(W, P)$ (see Pellegrino et al., 1977). The drawing-writing task used in Experiment 1 allows a direct assessment of crossmodality transfer latency and thus a test of these competing accounts.

\section{Method}

\section{Subjects}

The subjects were 42 undergraduates enrolled in introductory psychology courses at the University of New Mexico in Albuquerque. All were right-handed and native speakers of English.

\section{Materials and Apparatus}

The subjects were presented, on a computer monitor, with line drawings of common shapes and corresponding shape names that were computer generated, for ten concepts (heart, square, mitten, circle, bell, bottle, anchor, flag, cup, arrow; see Figure 3). The ten picture and ten word stimuli were devised to be equivalent in area (pictures: $M=7.80 \mathrm{~cm}^{2}$, range $=3.51-9.92 \mathrm{~cm}^{2}$; words: $M=7.75 \mathrm{~cm}^{2}$, range $=4.55-9.36 \mathrm{~cm}^{2}$ ). The stimuli subtended, on average, $4.67^{\circ}$ of horizontal visual angle (pictures: $M=3.03^{\circ}$, range $=2.22^{\circ}-4.13^{\circ} ;$ words: $M=6.30^{\circ}$, range $=3.71^{\circ}-7.73^{\circ}$ ). The horizontal visual angles of the word and picture stimuli fell within the range $\left(2.20^{\circ}-8.00^{\circ}\right)$ in which Theios and Amrhein (1989) found no differences in encoding latency for pictures $\left[t_{\mathrm{E}}(P)\right]$ and

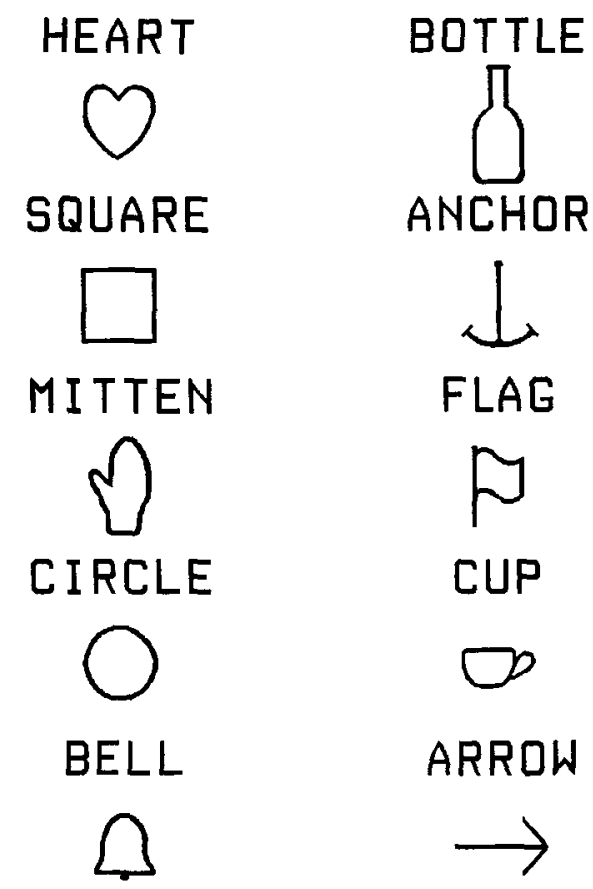

Figure 3. Stimulus ensemble used in the experiments. These stimuli are also used in "The Time It Takes Elderly and Young Individuals to Draw Pictures and Write Words," by P. C. Amrhein and J. Theios, 1993, Psychology \& Aging, 8, 200. Copyright 1993 by the American Psychological Association. Reprinted by permission. 
words $\left[t_{E}(W)\right]$. The subjects made their responses using an Apple computer graphics digitizer tablet and pen stylus interfaced to an Apple II computer system. The tablet was sampled (after the pentip switch was depressed) by the computer at a rate of 120 points per sec.

\section{Design and Procedure}

The subjects received 120 trials [ 10 stimulus concepts $\times 2$ input stimulus modalities (picture or word) $\times 2$ output task modalities (draw or write) $\times 3$ trial replications). In addition, the subjects received 20 practice trials randomly sampled from the experimental trial set. They were shown the set of word and picture stimuli prior to the practice trials and were instructed to be consistent across trials in their reproductions of the stimuli. For a given trial, a subject was presented with a "READY" prompt to place the pen at the start location indicated on the tablet (i.e., he or she was instructed to hold the pen tip slightly above the tablet surface over a centrally placed dot). After $4.5 \mathrm{sec}$, the subject was presented, on the screen, with the task prompt "WRITE" or "DRAW" (accompanied by a $265-$ or $530-\mathrm{Hz}$ tone) for $750 \mathrm{msec}$. After a 1.5 -sec blank period, a shape or shape-name stimulus was presented. Upon stimulus presentation, at the start location the subject began writing the shape name or drawing the shape (according to the task prompt), as quickly and accurately as possible. Production onset latency was measured from stimulus onset until the switch on the tip of the pen was depressed. On the monitor, the subjects received immediate dynamic feedback of their production; when the subjects finished their production, they then pressed the pen-tip switch at the "finish" spot designated on the tablet, which ended the trial. Trial productions were videotaped for subsequent error analysis. The experiment lasted approximately $60 \mathrm{~min}$.

\section{Results}

For Experiment 1, two analyses of variance (ANOVAs) were each conducted on the errors and onset latencies, with trial replication (first, second, or third), stimulus modality (word or picture), and task modality (write word or draw picture) as fixed factors. For each dependent measure, the first analysis treated subjects as the random factor $\left(F_{1}\right)$, while the second analysis treated the ten stimulus concepts as the random factor $\left(F_{2}\right)$. The actual statistics from these analyses are given in Appendix $\mathrm{A} ; M S_{\mathrm{e}}$ values for the various ANOVA sources of the latency analysis are given in Table 1. Effects and interactions reported as significant meet or exceed the .05 level of significance for subjects and concepts ANOVAs.

\section{Errors}

Onset latencies for trials on which errors occurred were excluded from data analysis. Errors consisted of trials in which an incomplete or incorrect production (with respect

Table 1

Experiment 1: Mean Square Error $\left(M_{e}\right)$

\begin{tabular}{lcr} 
& \multicolumn{2}{c}{ ANOVA } \\
\cline { 2 - 3 } \multicolumn{1}{c}{ Source } & Subjects $\left(F_{1}\right)$ & Concepts $\left(F_{2}\right)$ \\
\hline Replication (R) & 324,826 & 174,496 \\
Stimulus (S) & 159,155 & 106,046 \\
Task (T) & 418,048 & $2,286,750$ \\
$\mathrm{~S} \times \mathrm{T}$ & 215,263 & 29,075 \\
$\mathrm{~S} \times \mathrm{R}$ & 88,514 & 94,987 \\
$\mathrm{R} \times \mathrm{T}$ & 90,524 & 111,754 \\
$\mathrm{~S} \times \mathrm{R} \times \mathrm{T}$ & 66,243 & 73,371 \\
\hline
\end{tabular}

to modality or concept) occurred. These errors constituted only $2 \%$ of the data. There was a significant stimulus modality $\times$ task modality interaction, such that the percentage of errors on cross-modality trials (draw picture given word stimulus: $2.38 \%$; write word given picture stimulus: $2.70 \%$ ) was greater than that on within-mode trials (draw picture given picture stimulus: $1.35 \%$; write word given word stimulus: $1.59 \%$ ). Remaining effects and interactions from these analyses were nonsignificant.

Finally, onset latencies were also excluded from data analysis for trials on which the subject either prematurely depressed the pen-tip switch prior to task prompt or stimulus presentation or lifted the pen up from the tablet immediately after depressing the pen-tip switch rather than continuing with the production response. Both types of event represent failures to follow procedural aspects of task instructions and constituted $2.7 \%$ of the data. The frequency of these events decreased significantly with replications: For the first, second, and third replication, occurrences represented $4.58 \%, 2.23 \%$, and $1.19 \%$ of the data, respectively. (Because these procedural mistakes occurred prior to as well as after task prompt and stimulus presentation, only a subjects ANOVA contrasting replications was conducted.)

\section{Production Onset Latencies}

Drawing and writing onset latencies and standard errors for Experiment 1 are plotted in the left panel of Figure 4 as a function of stimulus modality and task modality, averaged over concepts, subjects, and replications. Also presented in that panel are the predicted latencies from the mathematical model to be discussed later. There was a significant effect for trial replication: Mean onset latencies for the first, second, and third replications were 838,743 , and $699 \mathrm{msec}$, respectively. There was no significant effect for stimulus modality (words: $761 \mathrm{msec}$, pictures: $759 \mathrm{msec}$ ). There was a significant effect for task modality, with onset to draw a picture $(812 \mathrm{msec})$ requiring $104 \mathrm{msec}$ more than onset to write a word $(708 \mathrm{msec})$. There was also a significant stimulus modality $\times$ task modality interaction, such that drawing a picture from a word stimulus $(857 \mathrm{msec}$ ) required $90 \mathrm{msec}$ more than drawing a picture from a picture stimulus $(767 \mathrm{msec})$, whereas writing a word from a word stimulus $(666 \mathrm{msec})$ required $85 \mathrm{msec}$ less than writing a word from a picture stimulus $(751 \mathrm{msec})$. Finally, these cross-modal latency increases (90 msec vs. $85 \mathrm{msec}$ ) did not differ significantly. Remaining interactions were nonsignificant.

\section{Discussion}

The findings of Experiment 1 are very straightforward: Overall, initiating the drawing of a picture requires more time than does initiating the writing of a word. This is likely due in part to the greater familiarity of writing over drawing (Van Sommers, 1984). Curiously, differential practice effects for the two task modalities were not found, suggesting that drawing may incur more strategic processes as well, such as taking more care to produce a "perfect" drawing (see also Paivio et al., 1989). 


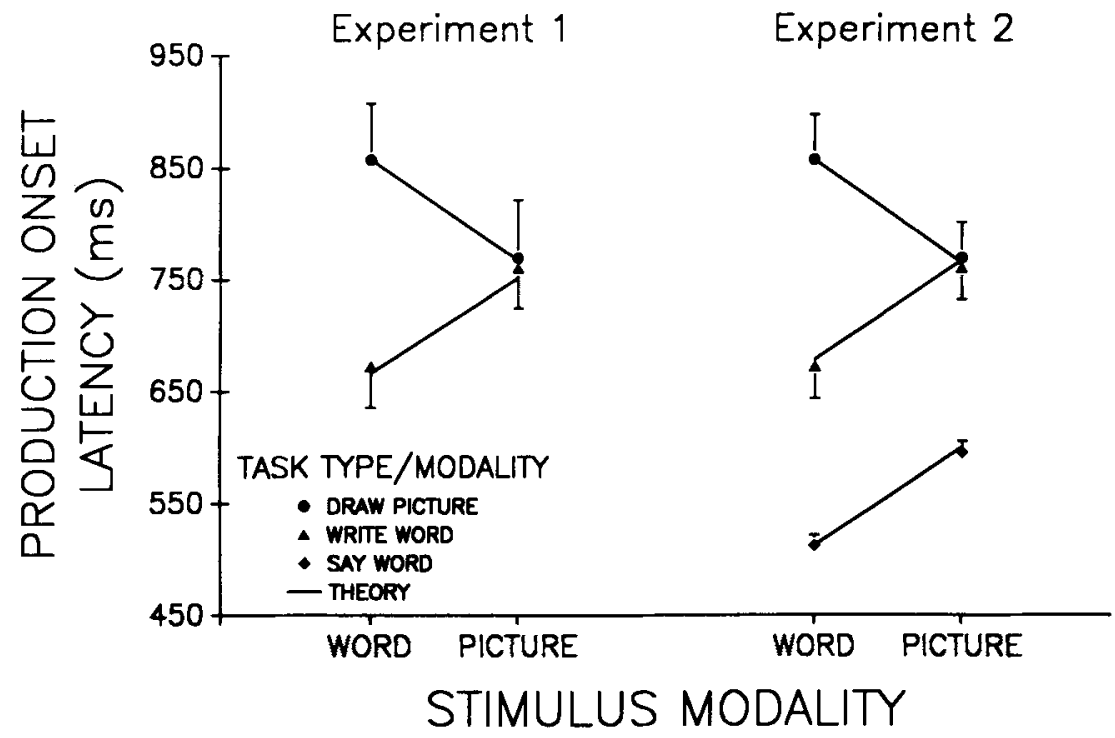

Figure 4. Mean production onset latency plotted as a function of experiment, stimulus modality, and task type/modality. Obtained latencies are the symbols; the lines are plotted according to the latencies predicted by the mathematical model. Standard error bars represent the weighted average of the standard errors for the subjects and concepts ANOVAs for a given stimulus modality-task type/modality condition.

The remaining findings indicate a balanced pictureword processing system. As was mentioned earlier, the advantage of the drawing-writing task over the traditional naming-reading task is that it provides an equally direct but comprehensive means to assess the two types of crossmodal translation-picture to word and word to picture. The dual-coding model, as interpreted earlier, predicts cross-modal translation asymmetry, with word-to-picture translation taking longer than picture-to-word translation [i.e., $t_{\mathrm{T}}(W, P)>t_{\mathrm{T}}(P, W)$ ]. However, such asymmetry was not found in Experiment 1. Thus, these data argue against extending the predictions of a dual-coding model based on episodic memory and imagery research to the temporal characteristics of referential processes between verbal and nonverbal processors.

\section{EXPERIMENT 2}

An important assumption of many amodal and dualcoding picture-word processing models concerns the independent functioning of specific subprocesses or sets of subprocesses. For example, as can be seen in Figure 1, cross-modal transfer from one surface processor (linguistic or pictorial) to the other surface processor (pictorial or linguistic) via the abstract conceptual processor should incur the same processing latency independent of the modality of the input stimulus, output task modality, or output task type (i.e., graphic production or speech). Even for the dual-coding model, cross-modal transfer from one surface/conceptual processor to the other surface/conceptual processor should be the same, regardless of output task (i.e., writing or speaking; see Figure 2). To test this assumption concerning output task type, the subjects in Ex- periment 2 performed not only the drawing-writing task used in Experiment 1 but, in addition, a naming-reading task (see Theios \& Amrhein, 1989). Specifically, as well as being an attempt to replicate the drawing-writing results of Experiment 1, the purpose of Experiment 2 was to determine whether equivalence exists between $t_{\mathrm{T}}(P, W)$ for the naming task, $t_{\mathrm{T}}(P, W)$ for the writing task, and $t_{\mathrm{T}}(W, P)$ for the drawing task. Equations for the namingreading task are as follows:

$$
\begin{aligned}
& \operatorname{Name}\left(P_{\mathrm{i}}, W_{\mathrm{j}}\right)=t_{\mathrm{E}}\left(P_{\mathrm{i}}\right)+t_{\mathrm{T}}\left(P_{\mathrm{i}}, W_{\mathrm{i}}\right)+t_{\mathrm{LP}}+t_{\mathrm{O}}(S) . \\
& \operatorname{Read}\left(W_{\mathrm{i}}, W_{\mathrm{j}}\right)=t_{\mathrm{E}}\left(W_{\mathrm{i}}\right) \quad+t_{\mathrm{LP}}+t_{\mathrm{O}}(S) .
\end{aligned}
$$

Here, Name is the observed response latency to begin to name a picture; Read is the observed response latency to begin to read a word out loud; and $t_{\mathrm{O}}(S)$ is the final increment of time needed to prepare for and initiate a speech response, corresponding to processing incurred by the speech production system (see Figure 1). Encoding parameters $t_{\mathrm{E}}(P)$ and $t_{\mathrm{E}}(W)$ and transfer parameter $t_{\mathrm{T}}(P, W)$ are defined for the amodal and dual-coding models as before. Finally, $t_{\mathrm{LP}}$ is the additional time taken to retrieve a phonetic code from the surface linguistic processor (amodal model) or the surface/conceptual linguistic processor (dual-coding model). Consistent with Equations 1-4 presented earlier, Equations 5 and 6 reflect current findings in the literature-namely, that naming a picture involves accessing semantic memory, but reading a word does not (Bajo, 1988; Glaser, 1992).

\section{Method}

\section{Subjects}

The subjects were 38 undergraduates enrolled in introductory psychology courses at the University of New Mexico in Albuquerque. 
All were right-handed and native speakers of English, and none had participated in Experiment 1.

\section{Materials and Apparatus}

The materials and apparatus were the same as those used in Experiment 1 , with the addition of a voice key used in the namingreading task.

\section{Design and Procedure}

The subjects performed the drawing-writing and the namingreading task in a counterbalanced order: half performed the drawingwriting task first and the other half performed it second. The design and procedure of the drawing-writing task were identical to those used in Experiment 1. For the naming-reading task, the subjects received 60 trials [ 10 stimulus concepts $\times 2$ stimulus modalities (picture or word) $\times 3$ trial replications]. In addition, they received 20 practice trials randomly sampled from the experimental trial set. For a given trial, a subject was presented with the prompt "ready" for $4.5 \mathrm{sec}$, followed by the prompt "speak" (accompanied by a $350-\mathrm{Hz}$ tone) for $750 \mathrm{msec}$. After a $1.5-\mathrm{sec}$ blank period, a shape or shape-name stimulus was presented. Upon stimulus presentation, the subject named the picture or read the word aloud, speaking into a microphone attached to the voice key, as quickly and accurately as possible. Production onset latency was measured from stimulus onset until the voice key detected the vocal response. These responses were taped for subsequent error analysis. The experimental session (which included both the drawingwriting and the naming-reading task) lasted approximately $80 \mathrm{~min}$.

\section{Results}

For Experiment 2, two separate ANOVAs were each conducted on the errors and production onset latencies for the drawing-writing and the naming-reading tasks. As in Experiment 1, for each dependent measure, one ANOVA treated subjects as the random factor $\left(F_{1}\right)$ and the other treated the ten stimulus concepts as the random factor $\left(F_{2}\right)$. For the drawing-writing task, fixed factors were trial replication (first, second, or third), stimulus modality (word or picture), and task modality (write word or draw picture). For the naming-reading task, fixed factors were stimulus modality (word or picture) and trial replication (first, second, or third). The actual statistics from these analyses are given in Appendix $\mathrm{A} ; M S_{\mathrm{e}}$ values for the various ANOVA sources of the latency analysis are given in Table 2. Effects and interactions reported as significant meet or exceed the .05 level of significance for subjects and concepts ANOVAs.

\section{Errors}

Drawing-writing task. Onset latencies for trials on which errors occurred were excluded from data analysis. Errors consisted of trials in which an incomplete or incorrect production (with respect to modality or concept) occurred. These errors constituted only $1.16 \%$ of the data. There was a significant stimulus modality $\times$ task modality interaction, such that the percentages of errors on cross-modality trials (draw picture given word: $1.32 \%$; write word given picture: $1.67 \%$ ) were greater than those on within-mode trials (draw picture given picture: $0.877 \%$; write word given word: $0.789 \%$ ). Remaining effects and interactions from these analyses were nonsignificant.
Table 2

Experiment 2: Mean Square Error $\left(M S_{e}\right)$

\begin{tabular}{lcr} 
& \multicolumn{2}{c}{ ANOVA } \\
\cline { 2 - 3 } Source & Subjects $\left(F_{1}\right)$ & Concepts $\left(F_{2}\right)$ \\
\hline & Drawing-Writing Task & \\
Replication (R) & 393,295 & 58,847 \\
Stimulus (S) & 82,752 & 136,937 \\
Task (T) & 557,120 & $1,778,003$ \\
$\mathrm{~S} \times \mathrm{T}$ & 149,244 & 241,748 \\
$\mathrm{~S} \times \mathrm{R}$ & 50,748 & 53,266 \\
$\mathrm{R} \times \mathrm{T}$ & 82,201 & 68,332 \\
$\mathrm{~S} \times \mathrm{R} \times \mathrm{T}$ & 61,969 & 77,834 \\
& Naming-Reading Task & \\
Replication (R) & 18,270 & 10,771 \\
Stimulus (S) & 13,987 & 14,840 \\
$\mathrm{~S} \times \mathrm{R}$ & 10,242 & 9,345 \\
\hline
\end{tabular}

Finally, onset latencies were also excluded from data analysis for trials on which the subject either prematurely depressed the pen-tip switch prior to task prompt or stimulus presentation or lifted the pen up from the tablet immediately after depressing the pen-tip switch rather than continuing with the production response. Both types of event represent failures to follow procedural aspects of task instructions, and constituted $3.09 \%$ of the data. The frequency of these events decreased significantly with replications: For the first, second, and third replications, occurrences represented $4.15 \%, 3.03 \%$, and $2.11 \%$ of the data, respectively. (As in Experiment 1, because these procedural mistakes occurred prior to as well as after task prompt and stimulus presentation, only a subjects ANOVA contrasting replications was conducted.)

Naming-reading task. Onset latencies for trials on which errors occurred were excluded from data analysis. Two kinds of response were considered errors for this task: incorrect verbal responses (incorrect word or no response) and extraneous or nonverbal noises (e.g., coughs, bumping the microphone, etc.). Collectively, these errors comprised only $1.32 \%$ of the data set. Analysis indicated no significant differences due to stimulus modality or replications; the interaction between stimulus modality and replications was likewise nonsignificant.

\section{Production Onset Latencies}

Drawing-writing task. Drawing and writing onset latencies and standard errors for Experiment 2 are plotted in the right panel of Figure 4 as a function of stimulus modality and task modality, averaged over concepts, subjects, and replications. Also presented in that panel are the predicted latencies from the mathematical model to be discussed later. There was a significant effect for trial replication: Mean onset latencies for the first, second, and third replications were 821, 759, and $719 \mathrm{msec}$, respectively. There was no significant effect for stimulus modality (words: $765 \mathrm{msec}$, pictures: $767 \mathrm{msec}$ ). There was a significant effect for task modality, with onset to draw a picture $(811 \mathrm{msec})$ requiring $89 \mathrm{msec}$ more than onset to write a word $(722 \mathrm{msec})$. There was also a significant stimulus modality $x$ task modality interaction, such 
that drawing a picture from a word stimulus $(857 \mathrm{msec})$ required $93 \mathrm{msec}$ more than drawing a picture from a picture stimulus $(764 \mathrm{msec})$, whereas writing a word from a word stimulus $(678 \mathrm{msec}$ ) required $89 \mathrm{msec}$ less than writing a word from a picture stimulus $(767 \mathrm{msec})$. Finally, these cross-modal latency increases $(93 \mathrm{msec}$ vs. $89 \mathrm{msec}$ ) did not differ significantly. Remaining interactions were nonsignificant.

Naming-reading task. Naming and reading onset latencies and standard errors for Experiment 2 are plotted in the right panel of Figure 4 as a function of stimulus modality averaged over concepts, subjects, and replications. Also presented in that figure panel are the predicted latencies from the mathematical model to be discussed later. Analysis yielded no significant effect for trial replication. There was a significant effect for stimulus modality, where onset to read a word $(512 \mathrm{msec})$ required $83 \mathrm{msec}$ less than onset to name a picture $(595 \mathrm{msec})$ - a difference that did not differ significantly from the crossmodal latency increases $(93 \mathrm{msec}$ and $89 \mathrm{msec}$ ) reported for the drawing-writing task. Finally, the stimulus modality $\times$ replications interaction was nonsignificant.

\section{Discussion}

The results of Experiment 2 replicate and extend the findings of Experiment 1. First, it was again found that overall processing of picture and word stimuli was equivalent in the drawing-writing task. Second, cross-modal trials exceeded their corresponding within-mode trials by the same latency. What is important is that this equivalent cross-modal latency increase occurred regardless of the output task, be it drawing, writing, or speaking. This finding suggests, tentatively, that the same functional pathway or pathways appear to be used, although in different directions, concerning translation from surface linguistic information (orthographic and phonetic codes) to surface pictorial information (graphic codes), and vice versa (see also Paivio et al., 1989). Importantly, this finding also indicates that certain stages of picture-word processing (e.g., cross-modal transfer) function independently of other stages (e.g., task modality and type). Finally, Experiment 2 replicated the finding of slower production onset latencies for drawing pictures relative to writing words, without a differential replications effect for the two production modalities, suggesting again that this effect is a stable, possibly strategic one. This finding will be discussed further in the context of the mathematical model of the results of Experiments 1 and 2, to be presented next.

\section{PARAMETER ESTIMATION AND MODEL FIT}

Based on the results reported for Experiments 1 and 2 above, the mean condition latencies for both experiments (shown in Figure 4) can be accounted for by a mathematical model which posits equivalent encoding and equivalent cross-modal transfer subprocess latencies for pictures and words. Concerning equivalent encoding latencies for pictures and words, because of the balance in the experimental design of the drawing-writing task, the main effect for stimulus modality provides an estimate of the additional latency to encode a word stimulus over that to encode a picture stimulus (or vice versa). Because it was nonsignificant for both experiments, a difference between $t_{\mathrm{E}}(P)$ and $t_{\mathrm{E}}(W)$ did not need to be incorporated into the mathematical model.

Concerning equivalent cross-modal transfer latencies, investigation of the significant stimulus modality $\times$ task modality interactions for Experiments 1 and 2 indicated that the two cross-modality transfer increases (drawing a picture from a word over drawing a picture from a picture, writing a word from a picture over writing a word from a word) were equivalent in absolute magnitude. As was detailed before, the dual-coding model predicts that the cross-modality transfer increases differ; specifically, $t_{\mathrm{T}}(P, W)<t_{\mathrm{T}}(W, P)$. However, this inequality was not found in the results of Experiments 1 and 2. By contrast, the amodal model of Theios and Amrhein (1989) predicts that $t_{\mathrm{T}}(P, W)=t_{\mathrm{T}}(W, P)$. Accordingly, the mathematical model makes no distinction between type of transfer parameter. Furthermore, it was shown in Experiment 2 that cross-modal transfer latency is the same for writing and naming responses, indicating that this transfer occurs independently of output task. Because of this, there are no differences between $t_{\mathrm{T}}(W, P)$ for the drawing task and $t_{\mathrm{T}}(P, W)$ for the writing and naming tasks that need to be incorporated into the model.

As was demonstrated by Theios and Amrhein (1989), the values of theoretical parameters allowed by the conditions of a task can be estimated using Donders' $(1869 / 1969)$ subtractive method, which is a variant of the modified method of moments (Atkinson, Bower, \& Crothers, 1965; Bush, 1963). Four estimated parameters which account for the differences observed among the various conditions of the two experiments are described below. These estimated parameters either are the same as those presented earlier in Equations 1-6, or represent composites of some of those parameters.

First, the parameter concerning base writing time, $B_{W}$, is the obtained mean onset latency to write a word given a word stimulus. This parameter represents a composite of three parameters given in Equation 1 (subscripts $i$ and $j$ removed): $t_{\mathrm{E}}(W)+t_{\mathrm{LO}}+t_{\mathrm{O}}(W)$. It is given below separately for Experiments 1 and 2, and then an average value is computed over both experiments:

$$
B_{W}=W r i t e(W, W) .
$$

Experiment 1:

$$
B_{W}=666 .
$$

Experiment 2:

$$
B_{W}=678 .
$$

Over Experiments 1 and 2:

$$
672=.5(666+678) \text {. }
$$


Second, the parameter concerning base reading time, $B_{R}$, is the obtained mean onset latency to read a word stimulus from Experiment 2. This parameter represents a composite of three parameters given in Equation 6 (subscripts $i$ and $j$ removed): $t_{\mathrm{E}}(W)+t_{\mathrm{LP}}+t_{\mathrm{O}}(S)$. It is given below:

$$
\begin{aligned}
& B_{R}=\operatorname{Read}(W, W), \\
& B_{R}=512 .
\end{aligned}
$$

Third, the estimate of transfer time increment for parameters $t_{\mathrm{T}}(W, P)$ and $t_{\mathrm{T}}(P, W)$ is obtained by setting the obtained condition latency means equal to Equations 1-6. For each experiment, to estimate $t_{\mathrm{T}}(W, P)$, the mean latency for drawing a picture given a picture (Equation 4) is subtracted from the mean latency for drawing a picture given a word (Equation 3). To estimate $t_{\mathrm{T}}(P, W)$ for the writing task, the mean latency for writing a word given a word (Equation 1) is subtracted from the mean latency for writing a word given a picture (Equation 2). These subtractions yield a pair of transfer parameter values for each experiment:

$$
t_{\mathrm{T}}(W, P)=\operatorname{Draw}(W, P)-\operatorname{Draw}(P, P) .
$$

Experiment 1:

$$
90=857-767 .
$$

Experiment 2:

$$
\begin{aligned}
93 & =857-764 . \\
t_{\mathrm{T}}(P, W) & =\text { Write }(P, W)-\text { Write }(W, W) .
\end{aligned}
$$

Experiment 1:

$$
85=751-666 .
$$

Experiment 2:

$$
89=767-678 .
$$

To estimate $t_{\mathrm{T}}(P, W)$ for the naming task of Experiment 2, the mean latency for reading a word (Equation 6) is then subtracted from the mean latency for naming a picture (Equation 5) (subscripts $i$ and $j$ removed):

$$
\begin{aligned}
t_{\mathrm{T}}(P, W) & =\operatorname{Name}(P, W)-\operatorname{Read}(W, W), \\
83 & =595-512 .
\end{aligned}
$$

There are no significant differences between $t_{\mathrm{T}}(P, W)$ and $t_{\mathrm{T}}(W, P)$ for either experiment, across task, or across experiments (i.e., concerning differences among the values in Equation 12). Therefore, a pooled estimate for a general transfer parameter, $t_{\mathrm{T}}$, is computed by averaging the two parameter values from Experiment 1 and the three parameter values from Experiment 2:

Over Experiments 1 and 2:

$$
88=.2[90+93+85+89+83] .
$$

Fourth, the parameter $t_{\mathrm{D}}$ represents the additional latency to initiate a drawing response over that required to initiate a writing response. As such, $t_{\mathrm{D}}$ is a composite of two subprocess latencies, $t_{\mathrm{P}}+t_{\mathrm{O}}(P)$ (with subscript $j$ removed; see Equations 3-4). It is determined separately for Experiments 1 and 2 and then an average value across experiments is computed:

$$
\begin{aligned}
t_{\mathrm{D}}= & .5[\operatorname{Draw}(W, P)+\operatorname{Draw}(P, P)] \\
& -.5[W r i t e(P, W)+\operatorname{Write}(W, W)] .
\end{aligned}
$$

Experiment 1:

$$
104=.5(857+767)-.5(666+751) .
$$

Experiment 2:

$$
89=.5(857+764)-.5(678+767) .
$$

Over Experiments 1 and 2:

$$
97=.5(104+89) .
$$

The four estimated parameters defined above generate a set of equations corresponding to task conditions. For the drawing-writing task (Experiments 1 and 2):

$$
\begin{aligned}
\operatorname{Write}(W, W) & =B_{W} . \\
\operatorname{Write}(P, W) & =B_{W}+t_{\mathrm{T}} . \\
\operatorname{Draw}(W, P) & =B_{W}+t_{\mathrm{T}}+t_{\mathrm{D}} . \\
\operatorname{Draw}(P, P) & =B_{W}+t_{\mathrm{D}} .
\end{aligned}
$$

For the naming-reading task (Experiment 2):

$$
\begin{aligned}
& \operatorname{Name}(P, W)=B_{R}+t_{\mathrm{T}} . \\
& \operatorname{Read}(W, W)=B_{R} .
\end{aligned}
$$

Using the values of the four parameters estimated above, the resultant predicted latencies produced by Equations 14-19 fit the ten obtained onset latencies (four from Experiment 1; six from Experiment 2) extremely well; the Root Mean Squared Error $(R M S E)$ between predicted and obtained latencies is only $5.1 \mathrm{msec}-$ less than a $0.2 \%$ error of prediction. Predicted and obtained latencies are given in Appendix B and plotted in Figure 4 according to experiment, stimulus modality, and task type/modality.

As mentioned above, estimated parameters $B_{W}, B_{R}$, and $t_{\mathrm{D}}$ are composites of other parameters given in Equations 1-6. Obviously, it would be of interest in subsequent research to empirically isolate those collapsed parameters. One place to start would be to separate additional latency due to output subprocesses [i.e., drawing: $t_{\mathrm{o}}(P)$, writing: $t_{\mathrm{O}}(W)$, and speaking: $\left.t_{\mathrm{O}}(S)\right]$ from that due to picture and word encoding $\left[t_{\mathrm{E}}(P)\right.$ and $t_{\mathrm{E}}(W)$, respectively] and retrieval $\left[t_{\mathrm{P}}, t_{\mathrm{LO}}\right.$, and $t_{\mathrm{LP}}$, respectively]. To do this, delayed drawing-writing and naming-reading tasks could be used and their results compared with those of the (immediate) drawing-writing and naming-reading tasks used in the present study. Using this delayed procedure for the drawing-writing task, for example, the subject would receive the task prompt and the stimulus some time prior to a "go" signal. The assumption would be that, as a result of giving the subject time to recognize the picture or word stimulus and retrieve the picture to be drawn or word 
to be written, the remaining onset latency would be due to the drawing or writing output subprocess.

Of relevance to a discussion of $t_{\mathrm{D}}$, in this regard, is an unpublished study conducted by Amrhein (1987). As stated earlier, $t_{\mathrm{D}}$ includes two subprocess latencies, $t_{\mathrm{P}}+$ $t_{\mathrm{o}}(P)$ (with subscript $j$ removed; see Equations 3-4), in the case where a picture was drawn from a word or picture stimulus. Accordingly, $t_{\mathrm{D}}$ represents a latency increment that could be due to the picture-retrieval subprocess and/or the drawing-output subprocess. Ascertaining the actual latency contribution of each subprocess is particularly important: If $t_{\mathrm{D}}$ was due to an increase in pictureretrieval latency from the surface pictorial processor (see Figure 1), it could be argued that retrieving a picture's graphic code $\left(t_{\mathrm{P}}\right)$ takes more time than does retrieving a word's orthographic code $\left(t_{\mathrm{LO}}\right)$. However, if it was due solely to an increase in the drawing-output initiation subprocess $\left[t_{0}(P)\right]$, no such argument concerning differences in picture and word retrieval could be made.

In the Amrhein (1987) study, subjects performed an immediate drawing-writing task like the one reported here, using a similar set of stimuli. These subjects also performed a delayed drawing-writing task, in which the task prompt and stimulus preceded a "go" response signal (a tone) by $2 \mathrm{sec}$. The results from the immediate drawingwriting task revealed the same symmetric pattern shown in Figure 4 concerning both the additional latency for cross-modality access and the additional latency for initiating a drawing over a writing response. By contrast, the results from the delayed drawing-writing task revealed no additional latency for cross-modality access (as expected assuming cross-modality access occurred prior to the onset of the "go" signal), but, again, additional latency to initiate a drawing over a writing response. Importantly, the additional time for drawing over writing was not significantly different from immediate $(101 \mathrm{msec})$ and delayed (94 msec) drawing-writing tasks. By inference, then, the additional latency for drawing over writing in the present study (i.e., $t_{\mathrm{D}}$ of $97 \mathrm{msec}$ ) is also likely due to the drawing-output subprocess $t_{\mathrm{O}}(P)$ rather than to the picture-retrieval subprocess $\left(t_{\mathrm{P}}\right)$, and, by implication, $t_{\mathrm{P}}$ is equivalent to $t_{\mathrm{LO}}$.

\section{CONCLUSIONS}

The present results argue for the amodal conceptual model of picture-word processing proposed by Theios and Amrhein (1989), and against a dual-coding model derived from episodic memory and imagery research (see Paivio, 1971, 1983, 1986; Pellegrino et al., 1977); they also argue against amodal theories that posit a temporal advantage for pictures in accessing an amodal memory processor and store (e.g., Bajo, 1988; Potter \& Faulconer, 1975; Smith \& Magee, 1980). Specifically, for the drawing-writing task there was no overall processing difference between picture and word stimuli. More importantly, cross-modality transfer latencies for drawing, writing, and naming tasks were found to be equivalent. Furthermore, the additional latency to initiate drawing over writing was determined to be due to the drawing-output subprocess, based on the results of an immediate and delayed drawing-writing study conducted by Amrhein (1987). The high degree of fit of the mathematical model to the condition latencies from both experiments underscores the balance in the picture-word processing system posited by Theios and Amrhein (1989).

The finding of this cross-modality translation symmetry is important: As was discussed earlier, differences found between picture-to-word and word-to-picture translation have been typically based on (usually across-experiment) differences in latencies to name pictures and generate images. The differences have indicated that producing a word for a picture is faster than generating an image from a word (Paivio, 1966; Snodgrass, 1980). However, it has been difficult to ascertain the nature of image-generation latency, because of its introspective nature. Furthermore, while Paivio et al. (1989) have presented apparent evidence that cross-modal translation involving naming and imaging appears to be symmetric, their dependent measure, a manual ready-to-produce response, did not assess graphic-production onset directly, and thus was still an intrinsically introspective measure. By contrast, the current experiments assessed an overt drawing-writing initiation response to familiar stimuli with unambiguous cross-modality representations, which required a speeded graphic production for both stimulus input-task output conditions. By mathematically determining the latencies of specific subprocess involved in task performance, no additional time was found for picture-word encoding, cross-modal transfer, or retrieval.

As was discussed earlier, the drawing-writing task used here offers a balanced solution to the incompleteness of the traditional naming-reading task. The drawing-writing task can also be implemented to address more comprehensively such issues as picture-word priming and Strooplike interference effects, which have typically been investigated using only the naming-reading procedure (or often picture naming alone).

For example, Bajo (1988) found that conceptually related word and picture primes facilitate picture naming, but not word reading. If that experiment were to be conducted using the current drawing-writing task, the expectation would be that such primes would also not facilitate word writing. Furthermore, if picture-word processing is balanced temporally, as posited by Theios and Amrhein (1989), then it should also be found that conceptually related word and picture primes facilitate picture drawing from a word, but not from a picture stimulus.

Likewise, the nature of Stroop-like interference observed for pictures and words (see, e.g., Glaser \& Dungelhoff, 1984; Glaser \& Glaser, 1989; Smith \& Magee, 1980 ) can be more comprehensively investigated by presenting target stimuli (pictures or words) flanked by interfering stimuli (words or pictures). Depending upon the task (drawing a picture or writing a word from the target stimulus), Stroop-like interference effects should arise. That is, drawing a picture from a target word stimulus should be impeded when the flanking stimuli are also pic- 
tures, relative to when the flanking stimuli are words or are not present. Correspondingly, writing a word from a target picture stimulus should be impeded when the flanking stimuli are also words, relative to when the flanking stimuli are pictures or are not present. Furthermore, relative to some baseline measure (e.g., flanking random dot patterns), the size of the temporal interference effect should be symmetric, according to the model of Theios and Amrhein (1989). In sum, the drawing-writing task provides a comprehensive way of obtaining convergent production-task evidence for aspects of semantic memory access.

Finally, individual differences in imagery ability (see, e.g., Kosslyn, 1980; Paivio, 1986) may impact the performance of the drawing-writing task. Specifically, these differences may influence the time to translate from a word to a picture, if retrieving a picture from a word stimulus for a drawing task requires image generation as previously suggested (Seymour, 1974). In the current model, this variable may impact both the transfer parameter, $t_{\mathrm{T}}(W, P)$, and the graphic code retrieval parameter, $t_{\mathrm{P}}$, with individuals with poorer imagery ability expected to have longer latencies for these parameters than individuals with better imagery ability. This and the other two issues briefly mentioned in the preceding paragraphs will be explored in a series of future investigations.

\section{REFERENCES}

AMrhein, P. C. (1987, May). The effects of task and stimulus information order on picture-word graphic production. Paper presented at the meeting of the Midwestern Psychological Association, Chicago.

Amrhein, P. C., \& Theios, J. (1993). The time it takes elderly and young individuals to draw pictures and write words. Psychology \& Aging, 8, 197-206.

Atkinson, R. C., Bower, G. H., \& Crothers, E. J. (1965). An introduction to mathematical learning theory. New York: Wiley.

BaJo, M. T. (1988). Semantic facilitation with pictures and words. Journal of Experimental Psychology: Learning, Memory, \& Cognition, 14, 579-589.

Balota, D. A., \& Chumbley, J. I. (1984). Are lexical decisions a good measure of lexical access? The role of word frequency in the neglected decision stage. Journal of Experimental Psychology: Human Perception \& Performance, 10, 340-357.

Balota, D. A., \& Chumbley, J. I. (1985). The locus of word-frequency effects in the pronunciation task: Lexical access and/or production? Journal of Memory \& Language, 24, 89-106.

BigGS, T. C., \& Marmurek, H. H. C. (1990). Picture and word naming: Is facilitation due to processing overlap? American Journal of Psychology, 103, 81-100.

Bush, R. R. (1963). Estimation and evaluation. In R. D. Luce, R. R. Bush, \& E. Galanter (Eds.), Handbook of mathematical psychology (Vol. 1, pp. 429-469). New York: Wiley.

Cattell, J. M. (1886). The time it takes to see and name objects. Mind, 11, 63-65.

Donders, F. C. (1969). On the speed of mental processes. Acta Psychologica, 30, 412-431. (Originally published in 1869.)

FALMAGNE, J. C. (1965). Stochastic models for choice reaction time with application to experimental results. Journal of Mathematical Psychology, 12, 77-124.
Farah, M. J., \& Kosslyn, S. M. (1981). Structure and strategy in image generation. Cognitive Science, 4, 371-383.

Fraisse, P. (1960). Recognition time measured by verbal reaction to figures and words. Perceptual \& Motor Skills, 11, 204.

FraISSE, P. (1964). Le temps de reaction verbale: I. Denomination et lecture [Verbal reaction times: I. Naming and reading]. Année Psychologique, 64, 21-46.

Fraisse, P. (1967). Latency of different verbal responses to the same stimulus. Quarterly Joumal of Experimental Psychology, 19, 353-355.

Fraisse, P. (1969). Why is naming longer than reading? Acta Psychologica, 30, 96-103.

Glaser, W. R. (1992). Picture naming. Cognition, 42, 61-105.

Glaser, W. R., \& Dungelhoff, F.-J. (1984). The time course of picture-word interference. Journal of Experimental Psychology: Human Perception \& Performance, 10, 640-654.

Glaser, W. R., \& Glaser, M. O. (1989). Context effects in Strooplike word and picture processing. Joumal of Experimental Psychology: General, 118, 13-42.

Harris, P. L., Morris, P. E., \& Bassett, E. (1977). Classifying pictures and words: Implications for the dual-coding hypothesis. Memory \& Cognition, 5, 242-246.

Kosslyn, S. (1980). Image and mind. Cambridge, MA: Harvard University Press.

LA HeIJ, W. (1988). Components of Stroop-like interference in picture naming. Memory \& Cognition, 16, 400-410.

Levelt, W. J. M., Schriefers, H., Meyer, A. S., Pechman, T., Vorberg, D., \& Havinga, J. (1991). The time course of lexical access in speech production: A study of picture naming. Psychological Review, 98, 122-142.

LUPKER, S., \& TheIos, J. (1975). Tests of two classes of models for choice reaction time. Journal of Experimental Psychology: Human Perception \& Performance, 104, 137-146.

McCauley, C., Parmalee, C. M., Sperber, R. D., \& Carr, T. H. (1980). Early extraction of meaning from pictures and its relation to conscious identification. Journal of Experimental Psychology: Human Perception \& Performance, 6, 265-276.

PaIvio, A. (1966). Latency of verbal associations and imagery to noun stimuli as a function of abstractness and generality. Canadian Journal of Psychology, 20, 378-387.

PaIvio, A. (1971). Imagery and verbal processes. New York: Holt, Rinehart and Winston.

Palvio, A. (1983). The empirical case for dual coding. In J. C. Yuille (Ed.), Imagery, memory and cognition (pp. 307-332). Hillsdale, NJ: Erlbaum.

Paivio, A. (1986). Mental representations. New York: Oxford University Press.

Paivio, A., Clark, J. M., Digdon, N., \& Bons, T. (1989). Referential processing: Reciprocity and correlates of naming and imaging. Memory \& Cognition, 17, 163-174.

Pellegrino, J. W., Rosinski, R. R., Chiesi, H. L., \& Siegel, A. (1977). Picture-word differences in decision latency: An analysis of single and dual memory models. Memory \& Cognition, 5, 383-396.

Potter, M. C., \& Faulconer, B. A. (1975). The time to understand pictures and words. Nature, 253, 437-438.

Schriefers, H., Meyer, A. S., \& Levelt, W. J. M. (1990). Exploring the time course of lexical access in production: Picture-word interference studies. Journal of Memory \& Language, 29, 86-102.

SeYMOUR, P. H. K. (1973). A model for reading, naming, and comparison. British Journal of Psychology, 64, 35-49.

Seymour, P. H. K. (1974). Generation of a pictorial code. Memory \& Cognition, 2, 224-232.

Seymour, P. H. K. (1979). Human visual cognition. New York: St Martin's Press.

Smith, M. C., \& Magee, L. E. (1980). Tracing the time course of picture-word processing. Journal of Experimental Psychology: General, 109, 373-392.

SNODGRASs, J. G. (1980). Towards a model for picture and word processing. In P. Kolers \& M. Wrolstad (Eds.), Processing of visible 
language (Vol. 2, pp. 565-584). New York: Plenum.

SNODGRASS, J. G. (1984). Concepts and their surface representations. Joumal of Verbal Leaming \& Verbal Behavior, 23, 3-22.

SNodgrass, J. G., \& McCullough, B. (1986). The role of visual similarity in picture categorization. Joumal of Experimental Psychology: Learning, Memory, \& Cognition, 12, 147-154.

TE LINDE, J. (1982). Picture-word differences in decision latency: A test of common-coding assumptions. Journal of Experimental Psychology: Learning, Memory, \& Cognition, 8, 584-598.
TheIos, J., AMrHeIN, P. C. (1989). Theoretical analysis of the cognitive processing of lexical and pictorial stimuli: Reading, naming, and visual and conceptual comparisons. Psychological Review, 96, 5-24.

Van Sommers, P. (1984). Drawing and cognition. Cambridge: Cambridge University Press.

WHEELDON, L. R., \& MONSELL, S. (1992). The locus of repetition priming of spoken word production. Quarterly Journal of Experimental Psychology, 44A, 723-761.

APPENDIX A

ANOVA Statistics

\begin{tabular}{|c|c|c|c|c|c|c|c|c|}
\hline \multirow[b]{3}{*}{ Source } & \multicolumn{8}{|c|}{ ANALYSIS } \\
\hline & \multicolumn{4}{|c|}{ Subjects } & \multicolumn{4}{|c|}{ Concepts } \\
\hline & $d f$ & $F_{1}$ & $p$ & $M S_{\mathrm{e}}$ & $d f$ & $F_{2}$ & $p$ & $M S_{\mathrm{e}}$ \\
\hline \multicolumn{9}{|c|}{$\begin{array}{l}\text { Experiment } 1 \\
\text { awing-Writing Task }\end{array}$} \\
\hline \multicolumn{9}{|l|}{ Errors } \\
\hline Replications (R) & 2,82 & 1.78 & .17 & .0302 & 2,18 & 2.54 & .11 & .0211 \\
\hline Stimulus (S) & 1,41 & .01 & .93 & .0234 & 1,9 & .01 & .93 & .0236 \\
\hline Task (T) & 1,41 & .56 & .46 & .0174 & 1,9 & .47 & .51 & .0207 \\
\hline$S \times T$ & 1,41 & 9.17 & .004 & .0158 & 1,9 & 6.69 & .03 & .0216 \\
\hline$S \times R$ & 2,82 & .58 & .56 & .0230 & 2,18 & .79 & .47 & .0168 \\
\hline $\mathbf{R} \times \mathbf{T}$ & 2,82 & 2.79 & .07 & .0154 & 2,18 & 3.29 & .06 & .0131 \\
\hline$S \times R \times T$ & 2,82 & .74 & .48 & .0154 & 2,18 & .52 & .61 & .0219 \\
\hline \multicolumn{9}{|l|}{ Outliers } \\
\hline Replications (R) & 2,82 & 13.7 & .0001 & .0366 & & & & \\
\hline \multicolumn{9}{|l|}{ Latencies } \\
\hline Replications (R) & 2,82 & 26.2 & .00 & 324,826 & 2,18 & 48.9 & .00 & 174,496 \\
\hline Stimulus (S) & 1,41 & .04 & .84 & 159,155 & 1,9 & .06 & .82 & 106,046 \\
\hline Task (T) & 1,41 & 32.4 & .00 & 418,048 & 1,9 & 5.93 & .04 & $2,286,750$ \\
\hline$S \times T$ & 1,41 & 44.6 & .00 & 215,263 & 1,9 & 330.3 & .00 & 29,075 \\
\hline $\mathbf{S} \times \mathbf{R}$ & 2,82 & .66 & .52 & 88,514 & 2,18 & .62 & .55 & 94,987 \\
\hline $\mathbf{R} \times \mathbf{T}$ & 2,82 & .16 & .85 & 90,524 & 2,18 & .13 & .88 & 111,754 \\
\hline$S \times R \times T$ & 2,82 & 2.32 & .10 & 66,243 & 2,18 & 1.23 & .09 & 73,371 \\
\hline \multicolumn{9}{|c|}{$\begin{array}{l}\text { Experiment } 2 \\
\text { wing-Writing Task }\end{array}$} \\
\hline \multicolumn{9}{|l|}{ Errors } \\
\hline Replications (R) & 2,74 & 2.06 & .14 & .0141 & 2,18 & 2.08 & .15 & .0131 \\
\hline Stimulus (S) & 1,37 & .63 & .43 & .0086 & 1,9 & .79 & .40 & .0069 \\
\hline Task (T) & 1,37 & .14 & .71 & .0141 & 1,9 & .05 & .82 & .0375 \\
\hline$S \times T$ & 1,37 & 4.46 & .04 & .0111 & 1,9 & 6.23 & .04 & .0079 \\
\hline $\mathbf{S} \times \mathbf{R}$ & 2,74 & 1.16 & .32 & .0144 & 2,18 & 1.00 & .39 & .0167 \\
\hline $\mathbf{R} \times \mathbf{T}$ & 2,74 & 1.79 & .17 & .0103 & 2,18 & 2.55 & .11 & .0072 \\
\hline $\mathbf{S} \times \mathbf{R} \times \mathbf{T}$ & 2,74 & .18 & .83 & .0143 & 2,18 & .11 & .90 & .0241 \\
\hline \multicolumn{9}{|l|}{ Outliers } \\
\hline Replications (R) & 2,74 & 6.07 & .004 & .0261 & & & & \\
\hline \multicolumn{9}{|l|}{ Latencies } \\
\hline Replications (R) & 2,74 & 10.2 & .00 & 393,295 & 2,18 & 67.9 & .00 & 58,847 \\
\hline Stimulus (S) & 1,37 & .06 & .80 & 82,752 & 1,9 & .04 & .85 & 136,937 \\
\hline Task $(\mathrm{T})$ & 1,37 & 16.0 & .00 & 557,120 & 1,9 & 5.01 & .05 & $1,778,003$ \\
\hline $\mathrm{S} \times \mathrm{T}$ & 1,37 & 63.5 & .00 & 149,244 & 1,9 & 39.2 & .00 & 241,748 \\
\hline $\mathbf{S} \times \mathbf{R}$ & 2,74 & 2.06 & .13 & 50,748 & 2,18 & 1.95 & .17 & 53,266 \\
\hline $\mathbf{R} \times \mathbf{T}$ & 2,74 & .10 & .91 & 82,201 & 2,18 & .11 & .89 & 68,332 \\
\hline $\mathbf{S} \times \mathbf{R} \times \mathrm{T}$ & 2,74 & 1.22 & .30 & 61,969 & 2,18 & .97 & .40 & 77,834 \\
\hline \multicolumn{9}{|c|}{ Naming-Reading Task } \\
\hline Replications (R) & 2,74 & .44 & .64 & 18,270 & 2,18 & .75 & .49 & 10,771 \\
\hline Stimulus (S) & 1,37 & 278.7 & .00 & 13,987 & 1,9 & 262.6 & .00 & 14,840 \\
\hline $\mathbf{S} \times \mathbf{R}$ & 2,74 & .00 & .99 & 10,242 & 2,18 & .01 & .99 & 9,345 \\
\hline
\end{tabular}


APPENDIX B

Obtained and Predicted Mean Production Onset Latencies (in Milliseconds)

\begin{tabular}{lccc}
\hline & \multicolumn{3}{c}{ Stimulus Modality } \\
\cline { 2 - 4 } Task Type/Modality & Word & Picture & Overall $M$ \\
\hline & Experiment 1 & \\
Draw & & & \\
Obtained $M$ & 857 & 767 & 812 \\
Predicted $M$ & 857 & 769 & 813 \\
Write & & & \\
Obtained $M$ & 666 & 751 & 709 \\
Predicted $M$ & 672 & 760 & 716 \\
Overall & & & \\
Obtained $M$ & 762 & 759 & 761 \\
Predicted $M$ & 765 & 765 & 765 \\
& Experiment 2 & \\
Draw & & & \\
Obtained $M$ & 857 & 764 & 811 \\
Predicted $M$ & 857 & 769 & 813 \\
Write & & & \\
Obtained $M$ & 678 & 767 & 723 \\
Predicted $M$ & 672 & 760 & 716 \\
Overall & & & \\
Obtained $M$ & 768 & 766 & 767 \\
Predicted $M$ & 765 & 765 & 765 \\
Speak & & & 554 \\
Obtained $M$ & 512 & 595 & 556 \\
Predicted $M$ & 512 & 600 & \\
\hline Note- $M M E$ & 5.1 & & \\
\hline
\end{tabular}

Note-RMSE $=5.1 \mathrm{msec}$.

(Manuscript received March 10, 1993;

revision accepted for publication October 4, 1993.) 